\title{
METHODOLOGY OF INTERPRETATION OF EUROPEAN CULTURAL HERITAGE
}

\author{
Liběna Jarolímková76 \\ Zuzana Míšková77
}

https://doi.org/10.31410/itema.2018.186

\begin{abstract}
The authors examine the topic of current challenges in interpretation of European cultural heritage in the context of changing tourism market, in particular of the structure and needs of visitors of tourism attractions in Europe.

The article presents the results of the first stage of an international project concerning this topic. It brings a brief overview and categorization of methods of European cultural heritage interpretation. The study examines twelve basic methods that can be used in the context of heritage interpretation in the framework of tourism (e.g. guiding service, printed materials, trails, expositions, visitors' centers, games, educational programmes, workshops, experience programmes, shows, events and audio-visual and digital media-based interpretation). The study evaluates advantages, disadvantages, suitability and sustainability of methods for three different segments of tangible cultural heritage: architecture, fine arts, religious monuments and three segments of intangible cultural heritage: music, traditions and customs and gastronomy.

The conclusion supports the needs of a variety of methods used for the European cultural heritage interpretation and the need to incorporate the issue of interpretation of European cultural heritage into visitor's management and to prepare a set of different interpretation methods for individual cultural sites and attractions.
\end{abstract}

Keywords: Tourism, Cultural Heritage, Interpretation, Methodology of Interpretation

\section{INTRODUCTION}

$\mathrm{T}$ The European Union declared the year 2018 as a year of European Cultural Heritage with the aim to promote access to cultural heritage and interpretative activities related to this common treasure of the continent. "Under the slogan 'Our heritage: where the past meets the future', the European Year of Cultural Heritage aims to contribute to a sustainable EU economy" [1]. Individual member countries organized a number of events to support awareness of European Cultural Heritage. These events addressed both professional and non-professional public. The authors of this paper study specific complementary issue - interpretation of European Cultural Heritage to tourism participants. Cultural attractions are very important and visiting them is a traditional part of itineraries of both organized and non-organized, group and individual tourism. [2] European tourism has recently been growing and its structure and consumer behavior of their visitors has been changing. These changes have resulted in the need to adapt interpretation of European Cultural Heritage to new trends in tourism.

Tourism subjects have been taught at the University of Economics in Prague already since 1959; currently the study programme is organized and guaranteed by the Department of Tourism at

\footnotetext{
${ }^{76}$ University of Economics, Prague, W. Churchill Sq. 1938/4, 13067 Prague, Czech Republic

${ }^{77}$ University of Economics, Prague, W. Churchill Sq. 1938/4, 13067 Prague, Czech Republic
} 
the Faculty of International Relations of the University of Economics in Prague. The aim of education in the field of tourism is preparation of top managers in all branches of the tourism industry, including interpretation of cultural heritage in tourism.

The topic Methodology of Interpretation of European Cultural Heritage through attractions in tourism is solved within an international project MIECAT. The Department of Tourism (Faculty of International Relations of the University of Economics in Prague) is a coordinator and researcher of this project. Other co-researchers are: University of Economics, Bratislava, Slovakia; Alexandru Ioan Cuza University, Iasi, Romania; University of Applied Sciences, Burgenland, Austria; Universidad Europea, Madrid, Spain; Fachhochschule des Mittelstands, Schwerin, Germany. The aim of the project is to create a course enabling students to acquire necessary competences in interpretation. Implementation of the project is planned for 2017 2020. The project is funded by EU Erasmus+ programme and will provide opportunity for exchange of scientific experience of all participating universities. With regard to diversity of historical development in individual countries and their approaches to interpretation, complexity of professional experience and findings is strengthened.

The aim of this paper is to present the outcomes of the first phase of the MIECAT project. This phase covered an overview of the research done up to now in the field of interpretation of cultural heritage, elaboration of this topic in professional literature, unification of terminology and creation of an overview of interpretation methodology used in the Czech Republic, Austria, Germany, Slovakia and Spain in three segments of tangible cultural heritage: architecture, fine arts, religious monuments and three segments of intangible heritage: music, traditions and customs and gastronomy. This paper brings an overview, analysis and evaluation of the methods applied for interpretation as well as identification of basic issues in the present interpretation of European Cultural Heritage.

\section{BASIS}

European tourism has been rapidly growing, its structure has been undergoing significant changes, and national scope of visitors has become more diversified. Europe welcomed 671 million tourist arrivals in 2017, which is by $8 \%$ more than in 2016. [3] More and more visitors from very different cultures with a very small and often only vague awareness of European culture are coming to Europe now. The number of tourists coming to Europe especially from Asia (particularly from China, Japan and India) and from America (the USA and Canada) is expected to grow. [4] Consumer behavior of visitors, their preferences while acquiring information about places visited both from the view of content and the form of the information submitted (e.g. preferring visual perception to texts, expecting entertaining elements and emotional messages) have been changing too. [5] Other important changes in requirements on interpretation result from changing preferences of ways and means of communication. These changes lead to the necessity to review the current approach to interpretation and to adjust interpretation of European Cultural Heritage to the above-mentioned trend.

"European Heritage sites are milestones in the creation of today's Europe and symbolize European ideals, values, history and integration." [6] Europe has rich history and broad cultural diversity. The concept of European Cultural Heritage in this paper corresponds to that of the UNESCO, which defines categories of tangible cultural heritage (movable and immovable) and intangible cultural heritage. [7] 
In Europe tradition of interpretation of European Cultural Heritage in tourism goes far into the history. Providing guiding services can be traced back to the 17th century; they are mentioned in the diaries written by noblemen on their chivalrous journeys. [8] Heritage interpretation was first defined by F. Tilden in 1957 as: "an educational activity which aims to reveal meanings and relationships through the use of original objects, by first-hand experience, and by illustrative media, rather than simply to communicate factual information". [9] In professional literature the theory of interpretation has been developed especially in Scotland and Canada since the 1970s. Together with increasing emphasis on protection of nature heritage used in tourism, professional literature of the last decade paid more attention to interpretation of nature attractions (development of specific programmes for visitors to national parks, geoparks, and development of heritage trails through interesting nature localities). In 2014 the European Association for Heritage Interpretation - Interpret Europe was founded to support interpretation of European Cultural Heritage. Its aim is to create a platform for international cooperation and exchange of experience. This association understands heritage interpretation as "structured approach to non-formal learning specialized in communicating significant ideas about a place to people on leisure. It establishes a link between visitors and what they can discover at heritage sites such as a nature reserve, a historic site or a museum." [9] Good interpretation is always based on first-hand experience and often on personal contact with staff on site. Good interpretation provokes visitors' curiosity and interest in the topic, reveals the significance, background and values of the site and helps people to enjoy a satisfying experience. [10] Some selected interpretation methods are described in the available literature [11], [12], particularly including the content and technical issues of providing guiding services in relation to their practical implementation. [8]. However, an updated overall comprehensive review of potential methods of interpretation and their systematic description, detailed analysis of management of European Cultural Heritage interpretation including economic evaluation of efficiency of individual interpretation methods are missing.

\section{METHODOLOGY}

A survey of interpretation methods was prepared by research into publicly available information about the offered ways of interpretation at the most visited cultural attractions in Europe. Categorization and follow-up analysis were prepared according to the below mentioned criteria. Data compilation was undertaken in the tourist season of 2018, evaluation of the data with the help of multicriterial analysis was prepared during October 2018.

The following criteria were used for evaluation of appropriateness of the method used:

- Amount of information,

- Meeting the goals of interpretation,

- Creativity of the message,

- Possibility of flexible adjustment of content of interpretation to different segments of visitors,

- Personal approach,

- Appropriateness for different kinds of cultural heritage (for all - limited),

- Possibility of language versions,

- Technical requirements,

- Organizational requirements,

- Requirements on the personnel,

- Costs. 
The evaluation was done by expert qualified evaluation with the help of a 1 - 4-point scale where a higher value of points represents a more appropriate level of evaluation characteristics of the interpretation method. Evaluation of currency of interpretation methods offered was assessed with monitored segments of European Cultural Heritage: architecture, religious monuments, fine arts, gastronomy, music, traditions and customs. A 5-point scale (0-4) (not at all, exceptionally, rarely, from time to time, very often) was used for the evaluation.

\section{METHODS OF EUROPEAN CULTURAL HERITAGE INTERPRETATION}

Approaches to defining the concept of interpretation differ in various sources. The authors of this paper incline to a broader definition of the concept of interpretation, i.e. they understand interpretation as communication with a visitor by various (even non-personal) ways, keeping in mind the principles of maintaining the content of interpretation, such as to communicate the information in context and reveal things and connections/relations not clear at first sight.

There are different aspects from which we can approach the evaluation of interpretation methods. Apart from evaluation how the goals of interpretation were met, it is possible to evaluate the benefits of interpretation for the visitor or to evaluate individual aspects of interpretation separately - content, aesthetic performance, emotional level, organizational and personnel provisions, technical solution, economic aspects (costs, revenues, and efficiency).

\section{CATEGORIZATION OF INTERPRETATION METHODS}

Methods of interpretation can be categorized from different points of view:

According to the place:

- methods used in authentic environment:

- Inside the attraction (e.g. castle),

○ Outdoors/in the field (e.g. urban reserve).

- methods used out of the authentic environment (e.g. in virtual environment, at school, in specific environment - interpretation centre, etc.).

According to duration:

- short (up to 1 hour),

- intermediate (several hours long),

- long-term (more days).

According to the means of communication used:

- verbal methods:

○ based on a spoken word,

○ based on a printed text,

- visual methods (based on visual materials, exhibits),

- audio methods (based on audio materials),

- multimedia methods.

According to the interpreter:

- personal,

- non-personal, without presence of a live interpreter - mediated by technical aids (e.g. audio-guide, boards, information panels), 
According to involvement of visitors:

- frontal methods (without involvement of visitors),

- interactive methods (with response of visitors),

- experience methods,

- emotional methods,

- dramatic methods,

- workshop methods (active participation of visitors),

- gamification methods.

According to the content of the message:

- professional message,

- edutainment,

- entertainment,

- experience,

- storytelling.

When planning interpretation of European Cultural Heritage for visitors in tourism the following aspects must be considered:

- Visitor's market segment (nationality, age, motivation, interest, experience, expectation, volume of time, personal preferences),

- Objectives of interpretation,

- Feasibility (protection of heritage, predisposition of the site, respect of genius loci, new technologies),

- Efficiency, sources (funds, human resources).

\section{EVALUATION OF ONTERPRETATION METHODS}

Twelve basic methods of interpretation were identified during the research. These methods are used in numerous diverse variations to present almost all kinds of tangible and intangible cultural heritage. Most common are classical guiding service and printed materials, intangible heritage is mostly interpreted through various events. Effectiveness and efficiency of individual methods of interpretation is individual and relates to the particular situation and type of visitors.

Table 1: Evaluation of interpretation methods: benefits

\begin{tabular}{|c|c|c|c|c|c|c|c|c|c|c|c|c|}
\hline & ס & 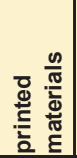 & $\frac{00}{\bar{\pi}}$ & 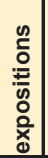 & 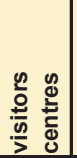 & 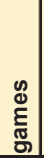 & 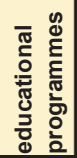 & $\begin{array}{l}n \\
\frac{0}{0} \\
\frac{c}{9} \\
\frac{1}{0} \\
\vdots \\
\vdots\end{array}$ & 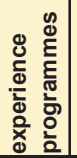 & $\begin{array}{l}n \\
3 \\
\frac{0}{n} \\
\frac{1}{n}\end{array}$ & $\overbrace{0}^{\infty}$ & $\stackrel{5}{\gtrless}$ \\
\hline amount of information & 4 & 2 & 2 & 4 & 4 & 1 & 4 & 4 & 4 & 3 & 2 & 4 \\
\hline goal of interpretation & 4 & 2 & 2 & 4 & 4 & 2 & 4 & 4 & 4 & 4 & 3 & 3 \\
\hline creativity & 4 & 1 & 2 & 4 & 3 & 3 & 4 & 4 & 4 & 4 & 4 & 3 \\
\hline flexibility & 3 & 1 & 1 & 2 & 1 & 2 & 4 & 4 & 4 & 4 & 2 & 4 \\
\hline personal approach & 4 & 2 & 1 & 2 & 1 & 2 & 4 & 4 & 4 & 4 & 3 & 1 \\
\hline type of European cultural heritage & 4 & 4 & 2 & 3 & 3 & 2 & 4 & 3 & 3 & 3 & 3 & 3 \\
\hline \multirow[t]{2}{*}{ language } & 1 & 4 & 2 & 2 & 2 & 3 & 1 & 1 & 2 & 1 & 3 & 4 \\
\hline & 24 & 16 & 12 & 21 & 18 & 15 & 25 & 24 & 25 & 23 & 20 & 22 \\
\hline technical demands & 3 & 4 & & 1 & 1 & 2 & 2 & 2 & 1 & 1 & 1 & 1 \\
\hline organizational demands & 1 & 4 & 3 & 1 & 2 & 2 & 1 & 1 & 1 & 1 & 1 & 3 \\
\hline personnel demands & 1 & 4 & 4 & 2 & 2 & 2 & 1 & 1 & 1 & 1 & 1 & 3 \\
\hline \multirow[t]{2}{*}{ costs } & 2 & 2 & 2 & 1 & 1 & 2 & 2 & 1 & 1 & 1 & 1 & 1 \\
\hline & 7 & 14 & 11 & 5 & 6 & 8 & 6 & 5 & 4 & 4 & 4 & 8 \\
\hline
\end{tabular}

Source: Authors'research

It is clear from the evaluation that the methods by which the goals of interpretation can be better achieved are technically, economically and organizationally more difficult. Less economically 
and organizationally demanding methods bring fewer possibilities in interpretation. Despite high costs according to the criteria given methods based on audio-visual technologies, guiding services and interpretation through exhibits and shows seem to be most appropriate regarding benefits/costs ratio.

Table 2: Currency of interpretation methods

\begin{tabular}{|c|c|c|c|c|c|c|c|c|c|c|c|c|}
\hline & 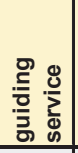 & 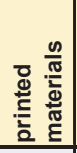 & $\frac{\infty}{\bar{N}}$ & $\begin{array}{l}0 \\
\frac{n}{0} \\
\frac{\vdots}{0} \\
0 \\
0 \\
\frac{0}{x} \\
0\end{array}$ & 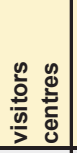 & $\begin{array}{l}\text { \& } \\
\text { E } \\
\text { హ్ }\end{array}$ & 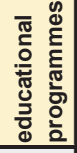 & $\begin{array}{l}0 \\
\frac{0}{0} \\
\frac{1}{0} \\
\frac{1}{2} \\
\vdots \\
\vdots \\
\end{array}$ & 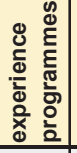 & $\begin{array}{l}n \\
3 \\
0 \\
\frac{n}{n} \\
\end{array}$ & 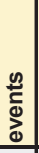 & $\stackrel{5}{4}$ \\
\hline architecture & 4 & 4 & 2 & 1 & 1 & 1 & 1 & 0 & 1 & 0 & 1 & 3 \\
\hline religious monuments & 2 & 4 & 1 & 1 & 0 & 0 & 0 & 0 & 0 & 0 & 1 & 1 \\
\hline fine arts & 3 & 2 & 1 & 4 & 0 & 2 & 4 & 4 & 2 & 1 & 2 & 3 \\
\hline gastronomy & 1 & 1 & 2 & 1 & 1 & 0 & 2 & 3 & 2 & 3 & 4 & 1 \\
\hline music & 2 & 2 & 1 & 2 & 1 & 0 & 2 & 1 & 1 & 2 & 3 & 2 \\
\hline \multirow[t]{2}{*}{ tradition and customs } & 3 & 2 & 1 & 2 & 1 & 0 & 3 & 3 & 3 & 3 & 3 & 2 \\
\hline & 15 & 15 & 8 & 11 & 4 & 3 & 12 & 11 & 8 & 9 & 14 & 12 \\
\hline
\end{tabular}

Source: Author's research

Regarding the currency of the offer, methods most frequently offered in the interpretation of the above-mentioned six groups of European Cultural Heritage (see table 2) are explanation of a guide and texts, but interpretation based on the use of audio-visual technologies has been developing. Interactive methods, such as edutraining programmes, events, workshops and shows are more common for interpretation of intangible heritage. Disadvantage of this form of interpretation is limited capacity and other restrictions in the offer of these programmes to foreign participants in tourism.

\section{PRELIMINARY FINDINGS}

Compiled information on the offered ways of interpretation of cultural activities in Europe was used to analyze these interpretation methods and to categorize them. Twelve basic methods of interpretation applied in many variations were identified.

Positive finding is that the scale of methods used is diversified and in many cases it gives a visitor option to choose the way of interpretation according to their personal preferences.

The methods of interpretation and their innovations are chosen according to the tradition/customs of a given place. Only seldom is the solution based on the analysis of the needs, it rather results from possibilities (or limitations) of the provider. Possible innovations usually come from individual intuition of property managers. Management of interpretation planning does not exist and effectiveness and organizational and economic demands of interpretation methods are not taken into account.

\section{DISCUSSION}

Research aimed at identification of the needs of visitors in tourism is planned to be conducted in the upcoming phase of the project. Other tasks to be solved are elaboration of a theory of interpretation planning and creating of methodology for assessment of economic efficiency of interpretation methods. 


\section{CONCLUSION}

The paper presents the results of the first phase of research within MIECAT project: analysis and brief evaluation of the used methods of interpretation and basic issues of current interpretation of European cultural heritage are identified.

The conclusion supports the need to incorporate the issue of interpretation of European cultural heritage into visitor's management and to prepare a set of different interpretation methods for individual cultural sites and attractions. This requires educating experts for planning and assessment of effectiveness of European cultural heritage interpretation.

\section{REFERENCES}

[1] Magdalena Pasikowska-Schnass, 2018. European Parliamentary Research Service. Cultural heritage in EU policies. [online] 2018 [accessed on 2018-11-14]. Available at: http://www.europarl.europa.eu/RegData/etudes/BRIE/2018/621876/EPRS_BRI(2018)62 1876 EN.pdf

[2] Vaníček, J., Šíp, J., Pachrová, S: The Changes in Czech Historic Towns and Tourism, p. $113-128$, "Transformation of Historical Cities' Functions in the Context of Tourism and Sustainability" University of Economy in Bydgoszcz, Poland, 2012. ISBN - 978-8361036-22-7

[3] UNWTO. 2018. World Tourism Barometer October 2018. Volume 16, Issue 4. ISSN: 1728-9246. [online] 2018 [accessed on 2018-11-14]. Available at: http://cf.cdn.unwto.org/sites/all/files/pdf/unwto_barom18_04_october_excerpt_pdf

[4] Sheivachman, A. Proposing Solutions to Overtourism in Popular Destinations: A Skift Framework. Skift - Oct. 23/2017 [online], [accessed on 2018-11-14]. Available at: https://skift.com/2017/10/23/proposing-solutions-to-overtourism-in-popular-destinationsa-skift-framework/

[5] Nevolová. M. Přestaň prezentovat, začni vyprávět. Grada. 2017, ISBN 978-80-247-56646

[6] European Commission. 2018. European Heritage Label. [online] 2017 [accessed on 201811-14]. Available at: https://ec.europa.eu/programmes/creative-europe/actions/heritagelabel en

[7] UNESCO, What is meant by "cultural heritage"? [online] 2017 [accessed on 2018-1114]. Available at: http://www.unesco.org/new/en/culture/themes/illicit-trafficking-ofcultural-property/unesco-database-of-national-cultural-heritage-laws/frequently-askedquestions/definition-of-the-cultural-heritage/

[8] Kubů, N., Kadlec. M., Faměrová. D-, Holub. J., Wagner. P.: Metodika průvodcovské činnosti na hradech, zámcích a dalších zpřístupněných památkách, NPÚ, 2014. ISBN 97880-7480-007-8

[9] Freeman Tilden. Interpreting our Heritage, University of North Carolina Press, 1957, ISBN 0-8078-4016-5

[10] Association for Heritage Interpretation Interpret Europe [online] 2018 [accessed on 201811-14]. Available at: http://www.interpret-europe.net/feet/home/interpret-europe/

[11] Ptáček. L., Růžička. T. Jak předkládat svět. Nadace partnerství Brno. 2012. ISBN 97880-904918-5-4

[12] Simon N. The Participatory Museum. MUSEUM, USA 2010. ISBN 978-0-615-34560-2 